\title{
LAS ILICITUDES PROBATORIAS EN MATERIA PENAL*
}

\author{
EVIDENTIAL UNLAWFULNESSES \\ IN CRIMINAL MATTERS
}

Emma Calderón Arias ${ }^{* *}$

\begin{abstract}
Resumen
El de las ilicitudes probatorias es un tema que se muestra en la doctrina y en la praxis jurídico penales como uno de los más importantes y, en tal contexto, reviste particular trascendencia lo atinente a la necesidad de garantizar la integridad y la autenticidad del material probatorio para que este llegue al juicio oral tal y como fue obtenido en el lugar de los hechos y, por esta vía, hacer efectivo el derecho al debido proceso. A lo anterior contribuye de manera significativa la cadena de custodia, cuyo cumplimiento evita, al menos en los aspectos mencionados antes, la existencia de ilicitudes probatorias y, en la misma medida, contribuye a la preservación de los derechos fundamentales y la observancia de las garantías procesales.
\end{abstract}

\section{Palabras claves}

Cadena de custodia, delito, ilicitudes probatorias, prueba, prueba ilícita.

\begin{abstract}
The unlawfulness of evidential is a subject that is shown in the legal doctrine and praxis as one of the most important and, in such context, is of particular importance to the need to ensure the integrity and authenticity of evidence so that this one reaches the oral trial as it was obtained in the place of the facts and, by this way, to make effective the right to the due process. The above contributes significantly to the chain of custody, whose fulfillment avoids, at least in the aspects mentioned above, the existence of evidential unlawfulnesses and, to the same extent, contributes to the preservation of fundamental rights and observance of procedural guarantees.
\end{abstract}

\section{Keywords}

Chain of custody, Crime, evidence, evidential unlawfulnesses, unlawful evidence.

\footnotetext{
* Informe parcial de investigación doctoral.

** Profesora de Derecho Penal y Criminalística. Facultad de Derecho, Universidad de la Habana.emma@lex.uh.cu, emma830913@gmail.com
} 


\section{Introducción}

La confesión fue la 'reina de las pruebas' en uno de los sistemas históricos de enjuiciamiento criminal que, de modo general, se encontraba desprovisto de garantías y en el que los elementos de prueba se obtenían de forma contraria a los derechos y libertades de las personas. La posterior reivindicación de las garantías y el diseño de un proceso penal respetuoso de los derechos fundamentales y de los límites que ellos imponen, como resultado del movimiento iluminista y de sus ideas de igualdad y de humanismo, permitió democratizar el proceso penal y entenderlo como una verdadera contienda entre partes -iguales-, acercándose de esta forma mucho más al ideal del debido proceso e introduciendo diversos mecanismos para amparar al acusado y a los demás sujetos del proceso.

En el anterior marco, este trabajo se ocupa de lo relativo a la licitud de las pruebas, a sus antecedentes y el estado actual de la cuestión, y se centra, por consiguiente, en las ilicitudes probatorias - prueba ilícita-, a propósito de lo cual adquiere total relevancia lo atinente a la cadena de custodia, entendida como una herramienta que minimiza el riesgo de nulidad o anulabilidad de los actos procesales.

\section{Fundamentos teóricos de las ilicitudes probatorias}

No existe consenso doctrinal sobre la definición de prueba ilícita: para De Diego (2001, p. 7), la actividad probatoria solo puede realizarse a través de la introducción de medios lícitos de prueba, lo cual pone de manifiesto que la obtención de las fuentes de prueba y su introducción en el proceso han de hacerse con escrupuloso respeto hacia los derechos individuales reconocidos en la Constitución -libertad personal, integridad física, psíquica y moral, intimidad personal y familiar, defensa, no autoincriminación, inviolabilidad del domicilio, etc.- que sirven como referentes para determinar si algún elemento de prueba ha sido obtenido con vulneración de los mismos y, por ende, no puede valorarse su resultado probatorio.

Para Gascón (2006, pp. 56-57), es prueba ilícita la que se obtiene con violación de las garantías constitucionales -la inviolabilidad del domicilio, el secreto de las comunicaciones, la transcripción de unas escuchas telefónicas sin cumplir los requisitos legales establecidos- o lesionando derechos constitucionales -el derecho a la defensa-, o a través de medios constitucionalmente prohibidos -la tortura, que vulnera el derecho a la integridad física, o una coacción para obtener declaraciones-.

Gascón (2006, p. 53), afirma que la prohibición de prueba ilícita no requiere regulación legislativa expresa, sino que deriva en forma directa de la Constitución por la posición preferente de los derechos fundamentales en el ordenamiento y su condición de inviolables. Dicho de otro modo, la regla de exclusión de la prueba ilícita deriva de la Constitución, porque su objeto es la protección de los individuos frente a actuaciones arbitrarias como las que tienen lugar cuando la policía se aparta de sus deberes legales y viola derechos; con todo, existen varios modos de articular este fundamento constitucional de la regla que pueden acarrear consecuencias distintas para su fortaleza. 


\section{El derecho a un proceso con todas las garantías.}

La regla de exclusión de la prueba ilícita está alojada en el derecho constitucional al proceso debido (due process of law); es la expresión de una garantía implícita en el sistema de los derechos fundamentales, pues la posición preferente que estos ocupan en el ordenamiento exige rechazar toda prueba obtenida con lesión de los mismos y esa garantía está plasmada en el derecho al debido proceso.

\section{La tesis del efecto preventivo o disuasorio de la exclusión.}

También puede sostenerse que la regla de exclusión de la prueba ilícita no tiene su fundamento constitucional en un concreto derecho, ni viene implícita y directamente exigida por la Constitución como la única salvaguarda efectiva de los derechos constitucionales, sino que reside en la necesidad de producir un efecto preventivo o disuasorio sobre las conductas que lesionan derechos.

Esto es lo que sucede en los Estados Unidos, cuya jurisprudencia, ya desde mediados de la década de los años setenta del siglo pasado y hasta la fecha, reconoce que la justificación canónica de la exclusionary rule no reside en un supuesto derecho constitucional subjetivo de la parte agraviada, sino en la necesidad de disuadir de la violación de los derechos (deterrent effect) y, de manera más precisa, en la necesidad de disuadir a los poderes públicos de realizar futuras lesiones a derechos constitucionales y, en especial, a la policía.

\section{La tesis española de la conexión de antijuridicidad.}

Se trata de una construcción teórica del Tribunal Constitucional español, mediante la cual se pretende explicar cuándo deben ser excluidas -o no- del proceso las pruebas obtenidas con lesión de un derecho fundamental. Esta tesis parte del presupuesto de que no toda prueba obtenida con vulneración de un derecho ha de ser considerada ilícita y, por lo tanto, excluida; lo será solo en determinadas circunstancias y de estas últimas da cuenta, la doctrina de la 'conexión de antijuridicidad', acorde con la cual las pruebas son inadmisibles cuando se lesiona un derecho fundamental y como consecuencia de ello se han obtenido pruebas, si, además de lo anterior, existe una relación de causalidad, una conexión de antijuridicidad entre la lesión y las pruebas.

Esta postura, valorada con anterioridad por Gascón (2006, pp. 68 ss.), responde al debate presentado alrededor de la prueba ilícita sobre su regulación en normas o no, pues, para él, la fuente directa es la Constitución, debido a la posición que tiene respecto a los derechos fundamentales; de otra opinión Ramos (2000, p. 19), para quien la prueba ilícita se refiere de forma exclusiva a la obtenida mediante la violación de los derechos y libertades fundamentales, de manera que, por definición, se concibe otra suerte de ilicitud probatoria solo ordinaria, que se ha dado en llamar prueba irregular, cuyos efectos no podrían ser parejos a la anterior, por mor del derecho fundamental a la prueba. 
Para Ramos (2000, p. 23), las diferencias entre la prueba ilícita y la irregular, en punto de la eficacia probatoria en el proceso penal, no son, sin embargo, apreciables en un primer grado, porque tanto la una como la otra carecen de virtualidad al respecto por lo cual dependen, en el segundo caso, de la naturaleza, la gravedad y la acumulación de irregularidades, y, sobre todo, de la indefensión provocada. En un segundo grado, el relativo a las pruebas relacionadas con ellas, para las derivadas de las pruebas ilícitas se impone la ineficacia como lógica consecuencia de una suerte de contaminación, mientras que, para las procedentes de las irregulares, no se produce tal radical consecuencia. Esta diferencia se resuelve en la práctica, por lo tanto, con la posibilidad de recuperar el material probatorio evidenciado por la prueba irregular, mediante su conversión en algún otro tipo de prueba subsidiaria, por lo general la testifical o la confesión, como modo de subsanación, posibilidad que es impensable en el caso de la prueba ilícita.

Una perspectiva interesante es la de Armenta (2011, p. 21), quien destaca dos aristas: la angloamericana, centrada en regular los medios de prueba y su obtención, sin que existan a priori reglas de exclusión, por lo cual en el adversarial system estadounidense la doctrina sobre la exclusionary rule se centra en contener los posibles abusos que puedan producirse en los derechos, por parte de los responsables públicos en la persecución de los hechos delictivos (Armenta (2011, p. 22); en tanto que, los sistemas continentales, enfocan sus esfuerzos en los medios de adquisición de las fuentes de prueba, aspecto regulado de manera específica bajo pena de nulidad.

En estos últimos, el respeto se centra en el principio de legalidad según el cual la obtención de la verdad debe seguir las pautas propias de un proceso establecido en forma legal. A partir de ahí, las configuraciones inciden de manera especial en el difícil equilibrio a que se someten intereses tan contrapuestos como dignos de tutela por ser legítimos; así, a título de ejemplo, y con base en una formulación general, la protección y castigo de las conductas infractoras y la tutela de intereses individuales, con la exclusión de concretos medios de prueba (Armenta, 2011, p. 22).

Tinoco (2001, p. 127), por su parte, explica que la exclusionary rule ha sido creada por la Corte Suprema de los Estados Unidos a partir de la IV Enmienda, referida a la inadmisión de las pruebas ilícitas u obtenidas con la violación de los derechos fundamentales. De acuerdo con la Doctrine of the fruits of the poisoned tree (doctrina de los frutos del árbol envenenado), esta regla no se restringe a la prueba directa, sino que también se aplica a la indirecta, es decir, a pruebas provenientes de las obtenidas en forma ilícita.

También en la doctrina argentina, Cafferata (1986, p. 14), distingue entre la obtención ilegal o irregular de la prueba y su incorporación al proceso, según el momento en que se produce. De suerte que la ilicitud puede producirse en dos instantes distintos: en la oportunidad de recolectar la fuente de prueba y con ocasión de la introducción de las mismas al proceso. Esta diferenciación es de interés desde que los supuestos de ilicitud extraprocesal son los que con mayor frecuencia se 
producen en la práctica; en efecto, la mayoría de los casos analizados hacen referencia al momento de la búsqueda, obtención y recogida de las fuentes de prueba, situándose, por lo tanto, en el marco de la fase de investigación policial o judicial.

En este sentido, Miranda (1996, p. 26) sistematiza una propuesta en atención al momento concreto en que se produce la ilicitud, dentro o fuera del proceso; así, distingue entre ilicitudes extraprocesales e intraprocesales. La primera, es aquella producida fuera de la esfera o marco del proceso propiamente dicho, a propósito de la obtención de la fuente de prueba, y afecta, por lo tanto, la labor de investigación de los hechos, es decir, a la búsqueda, recolección y obtención de las fuentes de prueba (por ejemplo, los documentos sustraídos u obtenidos delictivamente e incorporados después a la causa). Y, la intraprocesal, es aquella que aqueja a un acto procesal, es decir, la proposición, admisión y práctica de la prueba durante el proceso (verbi gratia, el empleo de medios coactivos en los interrogatorios del inculpado).

Frente a los criterios de clasificación de Cafferata (1986) y Miranda (1996), debe decirse no son del todo atinados cuando aseveran que la extraprocesal afecta la fase de investigación de los hechos, la búsqueda, recolección y obtención de las fuentes de prueba, pues esa fase es la llamada como preparatoria del juicio oral por lo cual no puede calificarse como extraprocesal sino antes del juicio oral. Y, en este sentido, la licitud de los actos es importante durante todo el proceso, pero requiere especial relevancia justo en las etapas de búsqueda, identificación, recolección, y obtención de los elementos de prueba, pues una vez que exista alguna vulneración de la cadena de custodia se puede hablar de prueba obtenida en forma ilícita, con las correspondientes consecuencias en el análisis pericial donde se arriba a los resultados.

Midón (2005, pp. 41-42), por su parte, propone otra clasificación según la causa de la ilicitud y expone que quienes participan de la concepción amplia de la prueba ilícita, esto es, de un criterio que no se ciñe a los supuestos de obtención y práctica de pruebas con vulneración de derechos o garantías constitucionales, en atención a la causa que origina la ilicitud, han de distinguir entre pruebas prohibidas por la ley de forma expresa, pruebas irregulares o ilegales, y pruebas inconstitucionales.

El concepto de prueba vedada por ley de forma expresa queda reservado para aquellos supuestos en los cuales exista una norma legal precisa y concreta de carácter prohibitivo. La irregular, defectuosa o ilegal, es aquella en cuya obtención se infringen la legalidad procesal ordinaria y se corresponde con el supuesto en el cual se desconocen las formalidades legales establecidas para su adquisición, esto es, sin ajustarse a las previsiones o al procedimiento fijado por la ley.

$Y$, en fin, las inconstitucionales son las obtenidas o practicadas con infracción de los derechos fundamentales de las personas y que dimanan de forma expresa o implícita de los textos constitucionales. En estos casos, para Midón (2005, pp. 49-53), la regla de exclusión opera, en términos más o menos generales, cuando una prueba que sirve para verificar la comisión de un delito se obtiene mediante 
violación, transgresión o superación de los límites esenciales establecidos en la Constitución, entendidos como fronteras de garantía dadas en función de valores que el constituyente juzgó supremos e inquebrantables -la dignidad del individuo y los atributos que de ella derivan-; como consecuencia de ello, la prueba resultará inadmisible desde la perspectiva procesal y deberá ser apartada o excluida como elemento de juicio.

Ahora bien, en relación con dicha regla de exclusión debe decirse que tiene voces a favor y en contra, provenientes de todos los sectores del pensamiento jurídico, cortes y tribunales inferiores, doctrinarios y académicos, que expresan y sustentan móviles y reparos, todos ellos de encomiable interés práctico y científico. Aquellas posturas que definen al proceso por la necesidad y obligación de investigar la verdad a ultranza y de manera absoluta, han de negar cualquier posibilidad de que existan prohibiciones de prueba, y con ello admitirán la eficacia del medio obtenido de manera ilegal. No habrá tema que no pueda ser investigado, ni método de averiguación que no deba ser utilizado.

Por el contrario, quienes hagan hincapié en una concepción menos absolutista, habrán de reconocer que junto al interés social en la averiguación de la verdad coexisten otras incumbencias y compromisos. Motivaciones y responsabilidades en ocasiones de superior valor y jerarquía que llevarán a impedir -0 , al menos, restringir- una búsqueda frenética a través de métodos siempre ilimitados. El razonamiento para apoyar la regla de exclusión va por el llamado discurso ético, con recursos de orden axiológico, a partir de la premisa de que al Estado y, por ende, a la administración de justicia, en tanto que función estatal, le es exigible un comportamiento adecuado a determinados principios éticos, en otras palabras, que en el proceso penal subyace un imperativo moral que restringe la actuación del órgano jurisdiccional a la hora de investigar y reprimir delitos. No se pretende significar que el Estado no pueda cumplir sus fines de justicia y seguridad, sino que esos objetivos no justifican el empleo de cualquier medio.

A su turno, Miranda (2013, p. 61) defiende -en criterio que es compartible- la utilización del término prueba ilícita, no solo por ser el de mayor aceptación en la actualidad, sino, sobre todo, por ser, en su opinión, el que mejor sirve para delimitar su concepto, sin perjuicio, de distinguir diferentes clases o modalidades en atención a la causa o causas que motivan su ilicitud. Por su parte, Silva (1963, p. 69) entiende que, al respecto, existen concepciones amplias y restrictivas: en las primeras, la prueba ilícita es aquella que atenta contra la dignidad humana. La importancia y trascendencia de este última está fuera de discusión, ya que la dignidad de la persona se constituye en pieza clave del concepto de prueba ilícita, por cuanto todo medio de prueba que atente contra la misma deviene ilícito y, por consiguiente, inadmisible.

También hay otro grupo de autores que, a partir de un concepto de ilicitud único para el orden jurídico en general, se identifican con la idea de violación de la norma o contrariedad con el derecho y definen la prueba ilícita como aquella 
contraria a una norma de derecho, esto es, obtenida o practicada con infracción del ordenamiento jurídico. El origen de la ilicitud de la prueba reside en que fue obtenida con violación de normas jurídicas, al margen de la categoría o naturaleza de estas últimas (constitucionales o legales, procesales o no) o incluso de disposiciones o principios generales (Devis, 1991, p. 95). Por otro lado, el concepto de ilicitud en el ámbito probatorio no siempre se identifica con el de hecho punible, pues, para que una prueba sea calificada de ilícita, no es necesario que la conducta encaminada a su obtención sea constitutiva de una infracción penal y, en esta medida, se opta por una concepción amplia de prueba ilícita.

Dentro de este grupo de autores, se concretan algunas precisiones en torno al rango de las normas violadas, en especial las constitucionales. En este sentido, Denti (1972, p. 281), en posición que también comparte Lozano (1990, p. 457), define prueba ilícita como aquella que se obtiene mediante la violación de derechos tutelados por normas diversas y, en primer lugar, por normas constitucionales. Se considera prueba ilícita aquella obtenida no solo mediante la infracción de normas constitucionales, sino, también, a través de la vulneración de normas con simple rango de ley.

Para la doctrina italiana, con Conso (1970, p. 2) como principal exponente, todas las normas relativas a las pruebas penales son normas de garantía del acusado, con base en lo cual su disciplina debe considerarse como un instrumento de defensa para el imputado y, en la misma medida, toda infracción de las normas procesales relativas a la obtención y práctica de prueba debe estimarse como prueba ilícita, por cuanto implica una vulneración del derecho a un proceso con todas las garantías. Y, por otro lado, las concepciones restrictivas (González, 1990, p. 31; Asencio, 1986, pp. 37-38; Tomé et al., 1993, p. 468; Martínez, 2003, p. 38; Arozamena, 1999, p. 83), en contraposición a las antes expuestas, son aquellas que circunscriben el concepto de prueba ilícita de manera exclusiva a la obtenida o practicada con violación de derechos fundamentales, en una opinión que también comparten De Diego (2001, p. 8), Gascón (2006, p. 57) y Ramos (2000, p. 20).

\section{La clasificación de las ilicitudes probatorias}

Son innumerables las divisiones de prueba ilícita que la doctrina elabora. Armenta (2011, p. 34), por ejemplo, señala que la ilicitud puede provenir de distintas causas: ser prueba legal y ser prohibida de forma expresa, diversificándose la prohibición en virtud de su objeto (prohibición de prestar testimonio para quienes están obligados a guardar secreto); afectar a determinados métodos de investigación (torturas, coacciones o amenazas); referirse a determinados medios de prueba (testimonio entre parientes, testimonios de referencia); o violentar derechos fundamentales; ser irregulares o resultar defectuosas. Puede producirse en diferentes momentos (antes o durante el mismo proceso); operar en beneficio del causante de la ilicitud o de un tercero o, en fin, consistir en actuaciones de diferentes sujetos (acusadores o acusado). 
Para Midón (2005, pp. 37-38), existen las pruebas ilícitas en sí mismas y las ilícitas por derivación; en las primeras, se trata del elemento que sirve para verificar un hecho y que fue practicado u obtenido directa e inmediatamente a través de un método o procedimiento ilegal; $y$, las segundas, remiten al acto en sí mismo lícito que permite comprobar una circunstancia fáctica, pero al que se accedió por intermedio de información obtenida desde una prueba anterior e recogida en forma ilícita. Así mismo, están las pruebas ilícitas materiales y testimoniales; materiales son todos los elementos físicos o corporales que vienen a ser, de manera directa o indirecta, recogidos - por ejemplo, la droga estupefaciente encontrada en el domicilio del imputado por un allanamiento ilegítimo, la cinta magnetofónica adquirida a través de una intervención clandestina de comunicaciones telefónicas, etc.-; $\mathrm{y}$, la testimonial, aquella que proviene en forma directa de las personas a través de sus dichos. Por su parte, Miranda (2013, p. 74) se refiere a dos clases de prueba ilícita: en primer lugar, la que se forma a partir del momento en que se produce la ilicitud (criterio temporal o cronológico) y, en segundo lugar, a relativa a la causa que motiva dicha ilicitud (criterio causal o material).

Según el momento en que se produce la ilicitud se puede distinguir entre la extraprocesal y la intraprocesal. La primera, se produce fuera de la esfera o marco del proceso propiamente dicho, en el momento de la obtención de las fuentes de prueba y, por lo tanto, afecta la labor de investigación de los hechos, es decir, a la búsqueda, recogida y obtención de las fuentes de prueba; en tal sentido, cualquiera de los intervinientes en la fase investigativa puede ser quien trabaje en la obtención de las fuentes de prueba, criterio que también comparten otros autores como Pastor (1986), López (1989, pp. 132-133), González (2006), Bernal (1990), Vegas (1993, pp. 123-124). Frente a esta tipología de prueba ilícita, Miranda (2013) refiere que hay criterios diferentes: por un lado, los que limitan la inadmisibilidad o exclusión de la prueba ilícita a la obtenida por autoridades o funcionarios públicos, pero no cuando se trata de particulares, posición que no comparte, pues cree que el tratamiento debe ser el mismo con independencia de quién o quiénes realicen esta labor de búsqueda y obtención de fuentes de prueba, a estos efectos carece de importancia el carácter de la persona (funcionario público o particular) que obtiene la fuente de prueba de forma ilícita dada la eficacia erga omnes de los derechos fundamentales.

La segunda, a su turno, afecta un acto procesal, es decir, a la proposición, admisión y práctica de la prueba durante el proceso, por ejemplo, emplear medios coactivos en los interrogatorios del inculpado.

Pastor (1986, p. 339), al clasificar las prohibiciones probatorias, las agrupa en dos apartados fundamentales, para lo cual se toma como base la distinción entre fuentes y medios de prueba: (a) aquellas derivadas de restricciones relativas a la investigación de los hechos -búsqueda y obtención de las fuentes de prueba- y (b) las que resultan de restricciones relacionadas con la incorporación de las fuentes de prueba al proceso -admisión y práctica de medios de prueba-. Por su parte, 
Cafferata (1986, p. 14) distingue entre la obtención ilegal o irregular de la prueba y su incorporación irregular al proceso.

En la doctrina italiana, Ramajoli (1995, p. 316) defiende la aplicación de la imposibilidad de utilizar las pruebas adquiridas con violación de las prohibiciones establecidas en forma legal, tanto en la fase de investigación y búsqueda de las fuentes de prueba como en la fase preparatoria propiamente dicha. Así las cosas, la ilicitud puede producirse en dos momentos distintos: el de la obtención de las fuentes de prueba y el de la incorporación de dichas fuentes al proceso; esta clasificación responde, a su vez, a la distinción de Carnelutti (1982, p. 67) entre fuentes y medios de prueba.

Otro criterio de clasificación está dado por las causas de ilicitud (Miranda, 2013, p. 79; Serra, 1991, p. 94; Midón, 2005, p. 40; Cafferata, 1986, p. 16). Para Miranda (2013, p. 80), se pueden diferenciar las pruebas prohibidas de forma expresa por la ley, las irregulares y/o ilegales y las obtenidas o practicadas con infracción de derechos fundamentales de las personas (las pruebas inconstitucionales).

Serra (1991, p. 95) se refiere a las causas que motivan la ilicitud del medio de prueba, por lo cual diferencia las prohibidas de forma expresa por la ley, las realizadas en forma distinta a la regulada por la ley, y las obtenidas o realizadas con infracción de los derechos fundamentales de las personas reconocidos en la Constitución. Para este autor, las últimas constituyen el capítulo más importante dentro de las pruebas ilícitas; sin embargo, las mismas no agotan el contenido de la prueba ilícita, sino que van más allá que las derivadas de la sola violación de los derechos fundamentales. En este sentido, es compartible el criterio de Miranda (2013) sobre una concepción amplia de prueba ilícita, no constreñida a aquellos supuestos de obtención o práctica de pruebas con vulneración derechos fundamentales, a la vez que reconoce que no toda ilicitud debe comportar, de manera necesaria, las mismas consecuencias en cuanto a la imposibilidad de utilizarlas en el proceso, por ejemplo, la ilicitud de la diligencia de entrada y registro en lugar cerrado no comporta siempre las mismas consecuencias; esta conclusión es aplicable a cualquier diligencia de investigación o a cualquier medio de prueba.

\section{El rango de la norma quebrantada como centro de la polémica}

Al no existir consenso en la definición de prueba ilícita, más allá de la nota común que la concibe como aquella obtenida con infracción del ordenamiento jurídico, las posturas se dividen entre quienes la refieren al ordenamiento jurídico en su integridad, los que la concretan en lo procesal y aquellos ceñidos a lo constitucional; en este marco, la polémica está en el rango de la norma quebrantada para considerar nulo el acto de prueba. No obstante, adviértase, otro término debatido es el de prueba prohibida, que, al decir de Asencio (1989, p. 75), no es aceptado a plenitud por la doctrina en atención a razones varias entre las que destaca la de ser tan solo un nombre gráfico que solo sirve para designar todo el conjunto variado de supuestos en que la prueba es inadmisible; además, dicha denominación supone un concepto equívoco en tanto que viene a indicar una multiplicidad de 
situaciones variables en función de la legislación en la que ha de operar, el reconocimiento o no expreso de su existencia, la escala de valores políticos, sociales, etc.

Un sector mayoritario de la doctrina, en el que se ubican Jaén (2002, p. 77), De Diego (2001, p. 7), Estrella (2001, p. 52) y Gimeno, Moreno \& Cortés (2001, p. 371), refiere que los actos de prueba serán nulos en tanto afecten derechos y libertades fundamentales establecidos en la Constitución, vulnerando per se el derecho a un proceso con garantías de forma general. A su turno, otro sector, en el que se destacan autores como Asencio (1986, p. 40; 1989, p. 121), Miranda (2013, pp. 157-158), Igartua (1995, p. 90), Sentís (1979, p. 248) y López (1989), no precisan distinción alguna en punto del rango de la norma vulnerada a la hora de los efectos que traería la validez o eficacia del acto probatorio, sino que de las mismas normas deriva el garantismo que traen consigo de forma intrínseca.

A su vez, están quienes restringen el espacio para la nulidad total de la prueba, pues la decisión sobre este supuesto debe darse en caso de quebrantamiento de normas jurídicas que no tienen que ser de rango constitucional, pero sí traer consigo la violación del derecho a un proceso garantista de forma general, al valorar el caso de que se trate y los intereses existentes, en tanto contienda de partes iguales (Ramos, 2000, p. 19; González-Cuéllar, 1990).

La esencia del problema se presenta, pues, en la determinación del rango de la norma quebrantada con la actividad probatoria y sus efectos válidos o nulos, en punto de lo cual es importante tener presente que en la investigación penal de un hecho delictivo la búsqueda de la verdad es uno de los aspectos de mayor importancia y ello, desde luego, explica las exigencias propias de legalidad y seguridad jurídica a la hora de determinar si los elementos de prueba analizados fueron tomados y conservados teniendo en cuenta las reglas de la cadena de custodia. De ahí que valga la pena valorar si dichos elementos de prueba se tomaron u obtuvieron -al igual que durante las etapas correspondientes- con transgresión de las reglas que garantizan los derechos fundamentales de los ciudadanos.

Resulta loable destacar que es inoperante establecer fórmulas a priori para la determinación de la prueba ilícita y, en tal aspecto, este trabajo coincide con la tercera tendencia, pues en este campo solo procede pronunciar pautas generales que orienten el camino a seguir tales como la necesidad de ponderar los intereses en conflicto, apreciar las circunstancias concretas de cada caso y, agréguese, observar que la vulneración de la formalidad procesal realmente produzca inequidad y desequilibrio entre las partes, lo cual es, en definitiva, la finalidad esencial del derecho a un proceso con todas las garantías.

Para algunos autores, la cuestión planteada trasciende el valor procesal de la cadena de custodia, en tanto que la jurisprudencia mantiene posiciones ambivalentes; no obstante, es mayoritaria la postura que considera las irregularidades en la cadena de custodia -casi siempre por la carencia de acreditación documental en alguna de sus fases- como prueba irregular y no ilícita, en cuyo caso poseería aptitud suficiente para anular su eficacia probatoria; lo anterior, con matices, puesto 
que, tratándose de una prueba irregular, debe atenderse a la naturaleza, la gravedad y la acumulación de irregularidades y, sobre todo, a la posible indefensión resultante.

Ahora bien, es necesario analizar qué ocurre cuando la cadena de custodia se rompe en alguno de sus eslabones, se desconocen las normas establecidas a tal fin, se falla en la obtención de las fuentes de prueba para la investigación contaminándolas o se irrespetan los derechos fundamentales y como todo ello puede conllevar a declarar ilícita la prueba. Pero, para ello, deben identificarse tres aspectos esenciales: el concepto de prueba ilícita, su clasificación y el rango de la norma quebrada. En cuanto a lo primero, una parte de la doctrina se refiere a la misma solo cuando se violan derechos fundamentales de las personas; al hilo de esto, resultan interesantes las posturas de Armenta (2011), quien alude a la subclasificación en las teorías angloamericana y continental y explica que esta última, en particular, gira en torno al principio de legalidad y, por ello, en la obtención de las fuentes de prueba se debe observar lo normado en ley, so pena de nulidad de facto; $y$, en sentido contrario, la de Miranda (2013), para quien lo más acertado es una concepción amplia, no solo relativa a la violación de derechos fundamentales sino que va más allá e incluye desde el momento de la obtención de las fuentes de prueba hasta su incorporación al proceso a través de los medios de prueba.

Respecto del segundo, la mayoría de la doctrina (Miranda, 2013; Cafferata, 1986) se refiere a la clasificación en torno al momento de la ilicitud, denominándolas extraprocesal e intraprocesal si se produce antes o durante el proceso. También, Midón (2005) se refiere a pruebas ilícitas en sí mismas y por derivación, y, dentro de las mismas, a pruebas ilícitas materiales -incluidas la recolección y el trabajo con las fuentes de prueba- $y$ testimoniales.

En lo atinente al tercero, las tendencias al respecto son, en primer lugar, las que remiten a la Constitución; en segundo lugar, las que proponen al ordenamiento jurídico de forma general y a una norma de índole procesal. Al respecto, parece poco atinado ir a la especificidad de la norma en sí y se tendrá que analizar caso por caso según sus propias particularidades, pronunciar pautas generales de orientación, ponderar los intereses en conflicto, apreciar las circunstancias concretas y sumar a todo ello el que la vulneración de la formalidad procesal conlleve inequidad y desequilibrio entre las partes, como esencia de ese proceso con todas las garantías.

\section{Consideraciones finales}

La cadena de custodia supone etapas que transcurren en pro de la validez de las fuentes de prueba obtenidas en la investigación del hecho con caracteres de delito $y$, en este sentido, es muy importante precisar lo que sucedería en caso de violar alguno de esos actos relativos a las fases. Resulta muy controvertido el debate sobre los efectos derivados de la ruptura de la cadena de custodia, en ese punto, expresa Figueroa (2015, p. 5), que, en principio, las autoridades policiales y judiciales son las que garantizan la preservación de la prueba y quien afirme la ruptura de la cadena de custodia debe probarlo. 
Desde luego, no debe admitirse como premisa aquella según la cual se deben presumir las actuaciones policiales como ilegítimas e irregulares, violatorias de derechos fundamentales, mientras no conste lo contrario. Debiendo plantearse la ruptura de la cadena de custodia acompañada de un nivel de concreción importante como, por ejemplo, en materia de drogas ilícitas, sostener que la sustancia analizada en el peritaje valorado como prueba de cargo no es la que la policía halló al acusado en el momento de su detención; en otras ocasiones, se reclama la nulidad de la prueba de $\mathrm{ADN}$, concretándose en la fase de recolección de los objetos de los que se extrae la muestra, alegando su posible contaminación, poniéndose en entredicho la cadena de custodia, entre otros tantos casos.

Así, la ruptura de la cadena de custodia no siempre acarrea como consecuencia que la prueba quede excluida, siempre que se logre acreditar que la prueba no fue alterada o modificada. Por lo que, para Del Pozo (2014, p. 152), la prueba tiene que haberse producido con las exigibles garantías procesales; debe haberse obtenido, por ende, con observancia de la normativa relativa a la obtención de fuentes de prueba, tanto en lo relativo a las normas de enjuiciamiento como a los principios, derechos y garantías constitucionales.

Y, en este sentido, es importante señalar que se distinguen tres tendencias en torno a la prueba ilícita: la relativa al derecho a un proceso con todas las garantías, por lo cual toda prueba que vaya en su contra es rechazada y declarada ilícita. La del efecto preventivo o disuasorio de exclusión, o exclusionary rule, enmarcada en la doctrina del fruto del árbol envenenado, acorde con la cual lo que derive de una prueba obtenida con violación de derechos y garantías se declara ilícito de facto. Y la de la conexión de la antijuridicidad, según la cual la prueba obtenida violando derechos fundamentales y lo que derive de la misma se considera ilícito y excluido, pero solo si existe una conexión de antijuridicidad (conexión de causalidad en lo antijurídico entre la lesión ocasionada y las pruebas obtenidas). Por consiguiente, el rango de la norma quebrantada es uno de sus pilares, resultando nulas aquellas pruebas que vulneren en forma directa los derechos fundamentales, y anulables las que contravengan una norma de menor jerarquía, dígase ley especial o cualquier otra normativa, en tanto este actuar podrá ser subsanable durante el transcurso del proceso.

Para que las pruebas sean admitidas en el proceso, convergen tres posturas: la de la admisibilidad o no de la prueba ilícita y una intermedia, en el caso de admitir (admisión, validez y eficacia) las pruebas obtenidas en forma ilícita, sin tener relevancia alguna el modo de obtención de las mismas, pues igual van a ser admitidas. La teoría de la no admisibilidad y apreciabilidad de la prueba obtenida de manera ilícita, donde se valora como importante el modo de obtención de las mismas. Y, para culminar, una teoría intermedia en cuya virtud se analiza la admisibilidad y apreciabilidad de las pruebas obtenidas de forma ilícita, según la ponderación de intereses en conflicto. 


\section{Referencias}

Armenta, T. (2011). La prueba ilícita (un estudio comparado) (2 ed.). Madrid; Buenos Aires: Marcial Pons, Ediciones Jurídicas y Sociales, S.A.

Arozamena, C. (1999). Consideraciones generales sobre la prueba ilícita. Actualidad Penal (4), 83-108.

Asencio, J. M. (1986). La prueba: garantías constitucionales derivadas del artículo 24.2. Poder Judicial (4), 33-48.

Asencio, J. M. (1989). Prueba prohibida y prueba preconstituida. Madrid: Trivium.

Bernal, J. (1990). Interceptación telefónica y grabaciones clandestinas en el proceso penal. Revista Universitaria de Derecho Procesal, (4), 361-417.

Cafferata, J. (1986). La prueba en el proceso penal. Buenos Aires: Depalma.

Carnelutti, F. (1982). La prueba civil (trad. Alcalá-Zamora y Castillo). Buenos Aires: Depalma.

Conso, G. (1970). Natura giuridica delle norme sulla prova nel processo penale. Revista di Diritto Processuale, (s. no.).

De Diego, L. (2001). Los medios de prueba. Tegucigalpa, Honduras: Cuadernos de estudios judiciales "Rafael Alvarado Manzano".

Del Pozo, M. (2014). Diligencias de investigación y cadena de custodia. Madrid, España: Editorial Jurídica Sepin.

Denti, V. (1972). Cientificidad de la prueba, en relación principalmente con los dictámenes periciales y la libertad de apreciación del juzgador (trad. S. Oñate). Revista de Derecho Procesal Iberoamericana, (2-3), 277-301.

Devis, H. (1991). Teoría general de la prueba judicial (T. I. 5 ed.). Buenos Aires: Víctor P. de Zabalía.

Estrella, M. (2001). La prueba ilícita. Tegucigalpa. Honduras: Cuadernos de estudios judiciales "Rafael Alvarado Manzano".

Ferrer, J., Gascón, M., González, D. \& Taruffo, M. (2006). Estudios sobre la prueba. México: Instituto de Investigaciones Jurídicas, Universidad Nacional Autónoma de México.

Figueroa, C. (2015). La cadena de custodia en el proceso penal. Madrid: EDISOFER.

Gascón, M. (2006). Fredoom of Proof? El cuestionable debilitamiento de la regla de exclusión de la prueba ilícita. En Ferrer, J., Gascón, M., González, D. \& Taruffo, M. (2006). Estudios sobre la prueba (pp. 47-88). México: Instituto de Investigaciones Jurídicas, Universidad Nacional Autónoma de México. 
Gimeno, V., Moreno, V. \& Cortés, V. (2001). Lecciones de Derecho Procesal Penal (2 ed.). Madrid: Colex.

González, J. L. (1990). La prueba obtenida ilícitamente con violación de los derechos fundamentales (el derecho constitucional a la prueba y sus límites). Revista de Derecho Procesal, (1), 29-44.

González, J. (2006). La prueba ilícita. Persona y Derecho. Revista de fundamentación de las instituciones jurídicas y de Derechos Humanos (54), 363-384.

González-Cuéllar, N. (1990). Proporcionalidad y derechos fundamentales en el proceso penal. España: Constitución y Leyes.

Igartua, J. (1995). Valoración de la prueba, motivación y control en el proceso penal. Valencia: Tirant lo Blanch.

Jaén, M. (2002). Tendencias actuales de la Jurisprudencia Constitucional Penal (las garantías del proceso penal. Madrid: Dykinson.

López, J. (1989). Las escuchas telefónicas y la prueba ilegalmente obtenida. España: Akal.

Lozano, M. (1990). Interceptaciones telefónicas y grabaciones clandestinas en el proceso penal español. Revista Universitaria de Derecho Procesal, (4, ed. especial), 453-458.

Martínez, E. (2003). Eficacia de la prueba ilícita en el proceso penal. Valencia: Tirant lo Blanch.

Midón, M. S. (2005). Pruebas ilícitas. Análisis doctrinario y jurisprudencial. Argentina: Ediciones Jurídicas Cuyo.

Miranda, M. (1996). El concepto de prueba ilícita y su tratamiento en el proceso penal. Barcelona: J.M Bosch Editor.

Miranda, M. (2013). Concepto de prueba ilícita y su tratamiento en el proceso penal. Especial referencia a la Exclusionary Rule Estadounidense. México: Ubijus.

Pastor, B. (1986). Eficacia en el proceso de las pruebas ilícitamente obtenidas. Justicia: revista de derecho procesal (2), 337-368.

Ramajoli, S. (1995). La prova nel processo penale. Padova: CEDAM.

Ramos, C. (2000). La prueba ilícita y su reflejo en la jurisprudencia. En AAVV. Manuales de formación continuada: La prueba en el proceso penal (pp. 15-74) (12), Madrid: Consejo General del Poder Judicial.

Sentis, S. (1979). La Prueba. Buenos Aires: Ediciones Jurídicas Europa-América.

Serra, M. (1991). Comentarios al Código Civil y Compilaciones Forales (T. XVI, Vol. 2., Madrid: Editorial Revista de Derecho Privado. 
Silva, V. (1963). La prueba procesal (T. I). Madrid: Editorial Revista de Derecho Privado.

Tinoco, Á. (2001). Fundamentos del sistema judicial penal en el Common Law. Sevilla: Universidad de Sevilla - Secretariado de Publicaciones.

Tomé, J.; De la Oliva, A.; Aragoneses, S.; Hinojosa, R. \& Muerza, J. (1993). Derecho Procesal Penal. Madrid: Centro de Estudios Ramón Areces.

Vegas, J. (1993). Presunción de inocencia y prueba en el proceso penal. Madrid: La Ley. 